\title{
Enhanced Tau Aggregation in the Presence of Amyloid $\beta$
}

Rachel E. Bennett, * Sarah L. DeVos, * Simon Dujardin, * Bianca Corjuc, ${ }^{*}$ Rucha Gor, ${ }^{*}$ Jose Gonzalez, * Allyson D. Roe, * Matthew P. Frosch, ${ }^{* \dagger}$ Rose Pitstick, George A. Carlson, ${ }^{\ddagger}$ and Bradley T. Hyman*

From the Department of Neurology,* MassGeneral Institute for Neurodegenerative Disease, Massachusetts General Hospital, Harvard Medical School, Charlestown, Massachusetts; the C.S. Kubik Laboratory for Neuropathology, ${ }^{\dagger}$ Massachusetts General Hospital, Harvard Medical School, Boston, Massachusetts; and the McLaughlin Research Institute, ${ }^{\ddagger}$ Great Falls, Montana

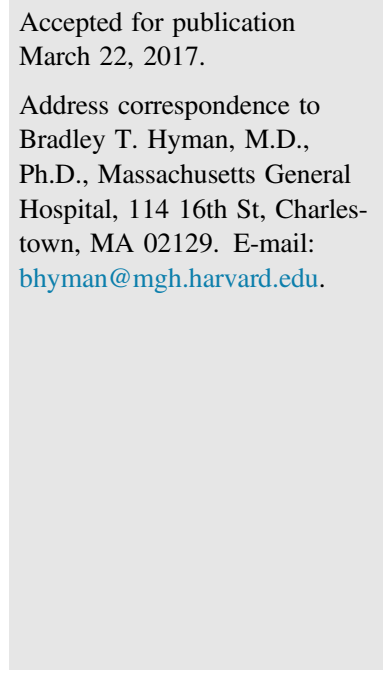

Accepted for publication

town, MA 02129. E-mail:

bhyman@mgh.harvard.edu.

In human patients with Alzheimer disease, tau-containing tangles and amyloid $\beta$ (A $\beta)$ plaques have distinct anatomical distributions, with plaques occurring in widespread areas of the cortical mantle, and tangles occurring in a stepwise, hierarchical manner from medial temporal lobe areas to ultimately affect limbic and association areas in the cortex. ${ }^{1,2}$ Interestingly, it has been observed that tangles rarely occur in the cortex unless plaques are present, leading to the hypothesis that plaques somehow trigger or interact synergistically with the spread of tangles. This is of clinical importance, because cognitive symptoms are most tightly tied to the presence of neurofibrillary tangles in the cortex. ${ }^{3,4}$ Thus, two competing ideas have emerged: plaques and tangles are two underlying pathologies in Alzheimer disease that simply co-occur in the cortex during the disease course, or the presence of plaques in the cortex synergistically accelerates tau pathology.
Animal models of tau and amyloid pathology broadly support the latter possibility, with synergistic effects observed in a variety of settings. ${ }^{5-13}$ For example, Götz et al ${ }^{14}$ injected synthetic preformed $\mathrm{A} \beta$ fibrils into the somatosensory cortex of young Tau(P301L) overexpressing mice and observed a fivefold increase in tau accumulation in the amygdala. Lewis et $\mathrm{al}^{15}$ crossed mice predisposed to the formation of amyloid plaques to tau-overexpressing mice and reported a sevenfold increase in tangle formation in multiple limbic brain structures. We recently demonstrated enhanced propagation of tau to connected neural system targets in a model of tau

Supported by National Institute on Aging (NIA) training grant NIH/NIA T32 AG000222 to the Division of Medical Sciences at Harvard University (R.E.B. and S.L.D.) and by NIH grants AG026249 and P50 AG005134.

R.E.B., S.L.D., and S.D. contributed equally to this work.

Disclosures: None declared. 
propagation from the entorhinal cortex. ${ }^{16}$ However, if (and how) these experimental phenomena reflect the human condition remains largely unknown.

\section{Materials and Methods}

\section{Human Tissue Selection}

Human tissue samples from entorhinal cortex, hippocampus, posterior parahippocampal gyrus, and cerebellum were obtained from the Neuropathology Core of the Massachusetts Alzheimer's Disease Research Center at the MassGeneral Institute for Neurodegenerative Disease. Tissue was coronally sliced at the time of autopsy, frozen between plates cooled to $-80^{\circ} \mathrm{C}$, and stored at $-80^{\circ} \mathrm{C}$. For these studies, samples were partially thawed and the above regions were divided into approximately $1-\mathrm{cm}$ blocks and then refrozen before homogenate preparation. The approximate location of tissue sampling is indicated in Figure 1A. Cases had previously been assessed by a neuropathologist and received a concurrent diagnosis as well as an Alzheimer disease neuropathologic change rating or $\mathrm{ABC}$ score ${ }^{17}$ using standard methods (Table 1). All cases had received Braak II stage ratings based on total tau immunostaining and Bielchowsky's silver stain. "No plaques" cases did not have plaques in any brain region examined [mean age $=79 \pm 14.2$ years $(\mathrm{SD})$ ]. "Plaques" cases had diffuse plaques throughout cortical and limbic brain structures in addition to sparse neuritic plaques [mean age $=85.2 \pm 8.5$ years $(\mathrm{SD})]$.

\section{Animals}

All animal experiments were performed in accordance with the Massachusetts General Hospital's and McLaughlin
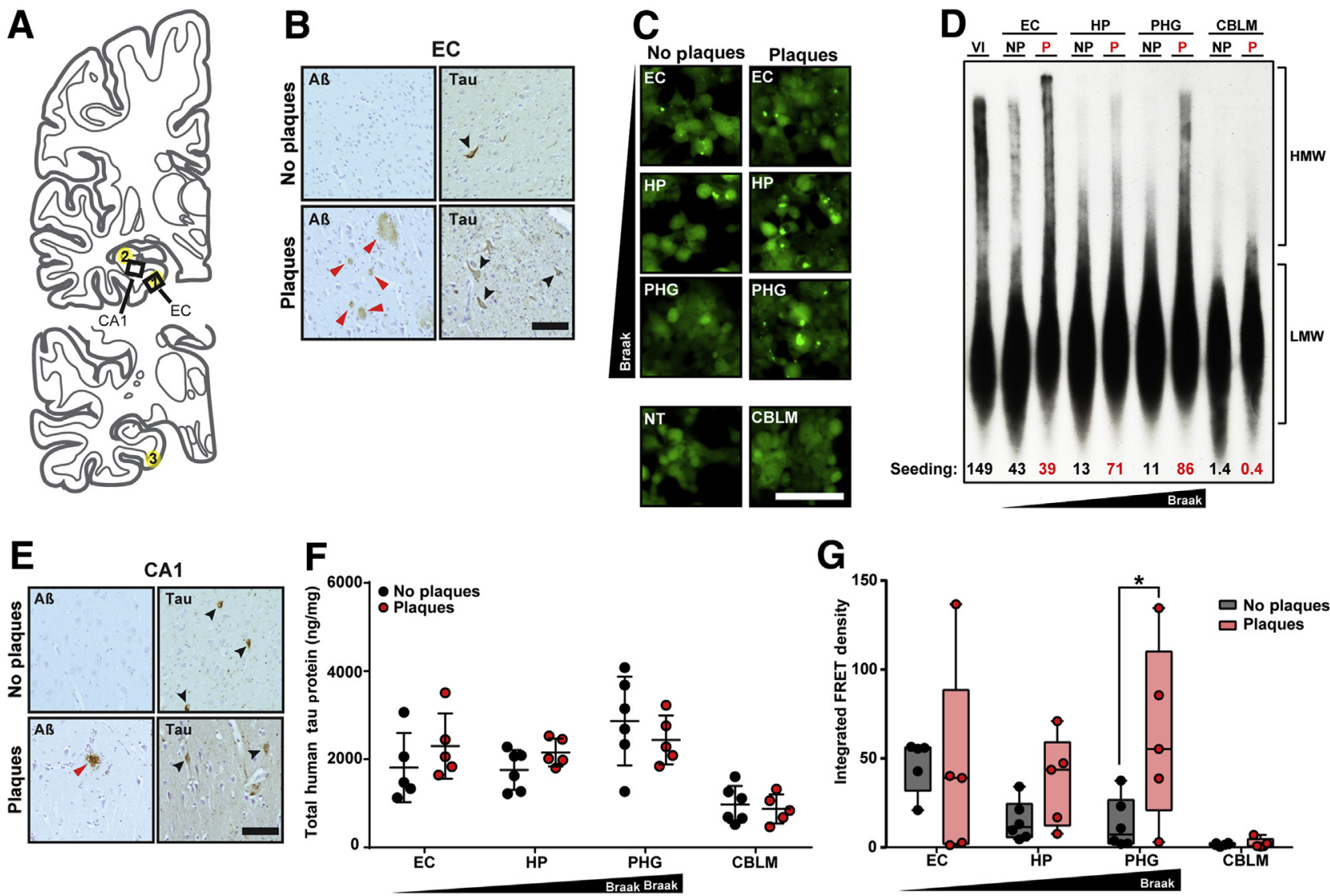

Figure 1 Plaques enhance tau aggregation in humans. A: Tissue homogenates were prepared from entorhinal cortex (EC) and hippocampus (HP) at the posterior end of the striatum. The posterior parahippocampal gyrus (PHG) was sampled at the level of the lateral geniculate nucleus approximately 2 to $3 \mathrm{~cm}$ posterior to the entorhinal cortex. Yellow highlighted areas indicate location of tissue sampling [1 (EC), 2 (HP), 3 (PHG)]. Boxed areas indicate locations where representative images were taken for $\mathbf{B}$ and $\mathbf{E}$. B and E: Paraffin sections from contralateral entorhinal cortex (B) and hippocampal CA1 (E) were stained for $A \beta$ plaques (red arrowheads) or tau (black arrowheads). Cases exhibiting no plaques have tau pathology in both the EC and CA1. Cases with plaques have similar tau pathology in addition to diffuse plaques in the EC and CA1. C: Aggregates in HEK cells are similar in brains with or without plaques in the EC, a region affected earliest in Braak staging, but are more prominent when cells are treated with plaque-containing brains from regions that develop tangle pathology with increasing Braak stage (HP and PHG). No aggregates are seen in nontreated cells (NT) or cells treated with homogenates from cerebellum (CBLM). D: SDD-AGE of representative cases to detect high-molecular-weight (HMW) and low-molecular-weight (LMW) tau using a polyclonal antibody against total tau. Comparisons of these Braak II cases are made versus a Braak VI sample (VI), which clearly contains both HMW and LMW tau species. HEK cell assay integrated FRET density values indicated at bottom. F: Total human tau protein measured by ELISA from prepared tissue homogenates. G: Quantification of HEK assay from C. Two-way analysis of variance. Data are expressed as means \pm SD. ${ }^{*} P<0.05$. Scale bar $=100 \mu \mathrm{m}(\mathrm{C})$. NP, no plaques; $\mathrm{P}$, plaques. 
Table 1 Characteristics of the Human Tissue Samples

\begin{tabular}{|c|c|c|c|c|c|c|c|c|c|}
\hline \multirow[b]{2}{*}{ Sample } & \multirow{2}{*}{$\begin{array}{l}\text { Age, } \\
\text { years }\end{array}$} & \multirow[b]{2}{*}{ Sex } & \multirow[b]{2}{*}{ PMI, hours } & \multirow[b]{2}{*}{ Braak/Braak } & \multicolumn{3}{|c|}{ ADNC rating } & \multirow{2}{*}{$\begin{array}{l}\text { Neuritic } \\
\text { plaques }\end{array}$} & \multirow[b]{2}{*}{ Concurrent diagnoses } \\
\hline & & & & & A & B & C & & \\
\hline No plaques 1 & 87 & $\mathrm{~F}$ & 6 & II & 0 & 1 & 0 & None & Lewy body disease \\
\hline No plaques 3 & 63 & $M$ & 10 & II & 0 & 1 & 0 & None & Parkinson disease \\
\hline No plaques 4 & 75 & $M$ & 38 & II & 0 & 1 & 0 & None & Multiple system atrophy \\
\hline No plaques 5 & 63 & $\mathrm{~F}$ & 24 & II & 0 & 1 & 0 & None & Cerebellar degeneration \\
\hline Plaques 2 & 95 & M & 9 & II & 1 & 1 & 2 & Sparse & None \\
\hline Plaques 3 & 73 & M & 24 & II & 3 & 1 & 1 & Sparse & Multiple system atrophy \\
\hline Plaques 4 & 91 & $\mathrm{~F}$ & 22 & II & 3 & 1 & 1 & Sparse & Cerebrovascular disease \\
\hline Plaques 5 & 82 & M & 6 & II & 3 & 1 & 1 & Sparse & Lewy body disease \\
\hline
\end{tabular}

Concurrent diagnoses were made at the Massachusetts Alzheimer's Disease Resource Center. Tau and amyloid $\beta$ immunostaining as well as silver-based histology were used to assess Braak stage and plaque pathology for ADNC rating.

F, female; M, male; ADNC, Alzheimer disease neuropathologic change; PMI, post-mortem interval.

Research Institute's Institutional Animal Care and Use Committees. Mice were housed under a 12-hour light/dark cycle and were given food and water ad libitum. B6.Cg-Tg(APPswe, PSEN1dE9)85Dbo/Mmjax mice (hereafter designated APP/PS1) were initially obtained from Jackson Laboratory (Bar Harbor, ME). APP/PS1 mice were crossed to the B6.Cg-Tg(Camk2a-tTA)1/Mmay tet transactivator strain that expresses tTA from the CK-tTA transgene exclusively in the forebrain. ${ }^{18}$ Double transgenic B6.CK-tTA, APP/PS1 males were selected as sires for the experimental cross to dams from the tetracycline-responsive element strain FVB-Tg(tetO-MAPT*P301L)4510/Kha/Jlws (rTg4510) to produce mice with the experimental genotype plus controls. All of the offspring of this cross share the FVBB6F1 background. Genotyping was performed preweaning using PCR protocols described previously. ${ }^{19-21}$ For this study, we selected four genotypes, each present in one of eight of the offspring. The experimental mice, designated APP/PS1rTg4510, carry the APP/PS1 array, the CK-tTA transactivator, and the $\mathrm{rTg} 4510$ tau responder transgenes ( $\mathrm{r}$ indicates regulatable because of the presence of both responder and transactivator transgenes). Other groups carry both the CK-tTA and the rTg4510 tau transgenes (rTg4510), APP/PS1 only, or CK-tTA only (wild type). Both B6 and FVB mice are susceptible to lethal effects of APP overexpression at approximately 100 days of age, ${ }^{22}$ requiring increased production to ensure adequate numbers of mice because up to half of the APP/PS1-expressing mice died prematurely.

These studies were performed using a total of 94 mice, both male and female at 4,6 , or 12 months of age. For 4month studies, $n=6$ wild type, $n=11$ APP/PS1, $n=6$ rTg4510, $n=11$ APP/PS1-rTg4510 mice were used. Not all animals in the 4-month group were prepared for both biochemistry and histological analysis. In the 6-month group, we used $n=5$ wild type, $n=4$ APP/PS1, $n=6$ rTg4510, and $n=6$ APP/PS1-rTg4510 mice. In the 12month group, we used $n=3$ wild type, $n=7$ APP/PS1, $n=7 \mathrm{rTg} 4510$, and $n=6$ APP/PS1-rTg4510 mice.
A separate group of 12-month-old mice $(n=4$ wild type, $n=4 \mathrm{APP} / \mathrm{PS} 1, n=3 \mathrm{rTg} 4510, n=5 \mathrm{APP} / \mathrm{PS} 1-\mathrm{rTg} 4510$ ) was used to measure $A \beta$ levels in cerebrospinal fluid (CSF). Before euthanasia, all mice were anesthetized with 5\% isoflurane and maintained at $2 \%$ for collection of CSF. During CSF collection from the cisterna magna, mouse body temperature was maintained using a heating pad and rectal thermal probe. CSF collection was performed successfully on most, but not all, mice. Immediately after this procedure, mice were deeply anesthetized with isoflurane and were euthanized by cardiac puncture. All animals were quickly perfused with chilled phosphate-buffered saline and brains were removed. The left hemisphere was dissected into cortex and hippocampus and frozen on dry ice for biochemistry, and the right side was drop fixed in 4\% paraformaldehyde (Electron Microscopy Sciences, Hatfield, PA).

\section{Immunohistochemistry}

Human tissue was formalin fixed and paraffin embedded before being cut into tissue sections $(8 \mu \mathrm{m}$ thick) and mounted onto slides. All sections were deparaffinized in xylene and a descending ethanol series and incubated in $3 \%$ $\mathrm{H}_{2} \mathrm{O}_{2}$ before immunolabeling. For $\mathrm{A} \beta$, sections were additionally treated with $90 \%$ formic acid for 5 minutes. Sections were rinsed with Tris-buffered saline (TBS) and incubated with 1:3000 rabbit polyclonal anti-tau (Dako, Glostrup, Denmark) or 1:200 mouse monoclonal anti-A $\beta$ (clone 6F/3D; Dako) for 1 hour at room temperature. Immunolabeling was visualized using Vectastain rabbit or mouse IgG horseradish peroxidase kits (Vector Laboratories, Burlingame, CA) and Vector peroxidase substrate kit diaminobenzidine (Vector Laboratories).

For mouse studies, hemispheres were fixed for 24 hours in $4 \%$ paraformaldehyde and then equilibrated in $30 \%$ sucrose in phosphate-buffered saline. Sections (40 $\mu \mathrm{m}$ thick) were sliced using a freezing microtome and were collected at 400$\mu \mathrm{m}$ intervals. For immunohistochemistry, sections were 
rinsed in TBS and endogenous peroxidases were quenched with $0.3 \% \mathrm{H}_{2} \mathrm{O}_{2}$. Sections were then blocked with $3 \%$ normal goat serum (Vector Laboratories) in $0.25 \%$ Triton-X TBS and then incubated with either rabbit polyclonal anti-A $\beta$ (IBL America, Minneapolis, MN) or mouse monoclonal AT8-biotin (Thermo Fisher Scientific, Waltham, MA) in blocking solution at $4{ }^{\circ} \mathrm{C}$ overnight. On day 2 , sections were washed in TBS and incubated in biotinylated secondary antibodies, followed by streptavidin-horseradish peroxidase containing $\mathrm{ABC}$ reagent (Vector Laboratories). Fresh diaminobenzidine was prepared from a tablet (Sigma-Aldrich, St. Louis, MO) and incubated with tissue for 2 to 3 minutes to develop color. Sections were mounted onto slides, dehydrated in ascending ethanol/xylene, and then coverslipped with Cytoseal XYL (Thermo Fisher Scientific).

For immunofluorescence, sections were washed and blocked following the same procedure but mouse anti-glial fibrillary acidic protein (EMD Millipore, Billerica, MA) or rabbit anti-Iba-1 (WAKO Chemicals USA, Richmond, VA) was used in addition to secondary antibodies conjugated to Alexa 488, Cy3, or Cy5. In one set of sections, slices were incubated in $0.005 \%$ (w/v in a solution of $50 \%$ ethanol and $50 \%$ TBS) thioflavin-S (ThioS) for 5 minutes after performing fluorescent immunolabeling. Sections were then rinsed three times for 30 seconds in a solution of $80 \%$ ethanol and $20 \%$ TBS, and then three times for 10 minutes in TBS before mounting onto slides. Slides were coverslipped with Fluoromount $\mathrm{G}$ (Southern Biotech, Birmingham, AL), sealed with clear nail polish, and imaged using a Zeiss AxioImager Z2 microscope (Zeiss, Thornwood, NY).

\section{Stereology}

After immunohistochemistry or ThioS labeling, stereological quantifications were performed using the Computer Assisted Stereological Toolbox version 2.3.1.5 (Olympus America, Melville, NY). ThioS-positive tangles and AT8-positive neurons were counted in three sections beginning with the first section containing hippocampal dentate gyrus. From each section, $15 \%$ of the total area of the cortex was counted using a randomized algorithm to yield count per $\mathrm{mm}^{2}$. Cortical volumes were calculated on the whole forebrain on brain slices of $40-\mu \mathrm{m}$ width with a $400-\mu \mathrm{m}$ interval, allowing for the extrapolation of the whole cortical volume for each animal. Glial fibrillary acidic protein-positive astrocytes, Iba1-positive microglial cells, ThioS-positive neuritic plaque number and surface were counted using ImageJ version 1.49m (NIH, Bethesda, MD; http://imagej.nih.gov/ij). These data were normalized on the counted surface for each animal, giving a number of events per $\mathrm{mm}^{2}$. All counting was conducted blinded to genotype (S.D.).

\section{Homogenate Preparation and Western Blotting}

Protein homogenates were prepared by placing the thawed tissue in a 2-mL glass dounce homogenizer with $200-\mu \mathrm{L}$ phosphate-buffered saline and homogenizing with 30 up/down strokes. The homogenate was subsequently centrifuged at $3000 \times g$ for 10 minutes at $4^{\circ} \mathrm{C}$, and the supernatant was collected. The pellet was saved for sarkosyl extraction. A bicinchoninic acid assay (Thermo Scientific Pierce, Rockford, IL) was performed to determine the total protein concentration. For sarkosyl extraction, pellets from the $3000 \times g$ spin were rehomogenized in buffer containing $20 \mathrm{nmol} / \mathrm{L}$ Tris- $\mathrm{HCl}, 0.15 \mathrm{~mol} / \mathrm{L} \mathrm{NaCl}, 1 \mathrm{mmol} / \mathrm{L}$ EGTA, and $1 \mathrm{mmol} / \mathrm{L}$ dithiothreitol. Triton- $\mathrm{X}$ was added at a final concentration of $1 \%$, and samples were incubated at $37^{\circ} \mathrm{C}$ for 30 minutes, then centrifuged for 30 minutes at 100,000 $\times g$. Supernatant was collected, and the pellet was resuspended in buffer, then incubated with $1 \%$ sarkosyl at $37^{\circ} \mathrm{C}$ for 30 minutes. After centrifugation at $100,000 \times g$, the supernatant was collected (sarkosyl-soluble extract) and the pellet was resuspended in $8 \mathrm{~mol} / \mathrm{L}$ urea with sonication and centrifuged at $100,000 \times g$. Supernatant was again collected (sarkosyl-insoluble extract). Protein concentrations were determined by bicinchoninic acid assay, and approximately $10 \mu \mathrm{g}$ of protein was loaded per well on a $4 \%$ to $12 \%$ bis-tris SDS-PAGE in MES buffer (Invitrogen, Carlsbad, CA). After transfer to nitrocellulose (mouse) or polyvinylidene difluoride (human), blocking was performed using Odyssey blocking buffer (Li-Cor Biosciences, Lincoln, NE), and rabbit polyclonal total tau antibody $(1: 1000$; Dako) was applied overnight. Infrared secondary donkey anti-rabbit 800 (1:5000; Li-Cor Biosciences) and an Odyssey Infrared Imaging System (Li-Cor Biosciences) were used to visualize the blot.

Phospho-tau blots were run under similar conditions, but rabbit polyclonal antibodies specific for pT181, pS199, pT205, pT231, pS396, pS400, and pS422 were applied $(1: 1000$; Invitrogen) as well as chicken anti- $\beta$-actin (1:1000; AbCam, Cambridge, MA) or mouse anti- $\beta$-actin (1:1000; Sigma-Aldrich). For phospho-tau pS262/pS356, the mouse monoclonal 12E8 was used (1:1000; Elan Pharmaceuticals, Dublin, Republic of Ireland). For detection of total tau, samples were probed with rabbit polyclonal anti-tau (1:1000; Dako). After overnight incubation, blots were visualized using donkey anti-rabbit IgG 800 and either goat anti-chicken IgG 680 or donkey anti-mouse IgG 680 (1:5000; Li-Cor Biosciences). Images of uncropped Western blots are available (Supplemental Figures S1 and S2).

\section{ELISAs}

Tau enzyme-linked immunosorbent assays (ELISAs) were performed using the total human tau ELISA kit (Invitrogen) and following the manufacturer's instructions. For cortex homogenates, samples were first diluted to $5 \mathrm{mg} / \mathrm{mL}$ and then $100 \mu \mathrm{L}$ of a 1:40,000 dilution in standard diluent was loaded per well. For CSF, $2.5 \mu \mathrm{L}$ of CSF was loaded in a total volume of $100 \mu \mathrm{L}$ (for a 1:40 dilution). Four-parameter logistic regression was used to fit the standard curve and determine the tau concentration in samples. $A \beta 1-42$ was 
detected using a commercial human/rat abeta42 ELISA kit (WAKO Chemicals USA), which detects the quantity of $\mathrm{A} \beta(\mathrm{x}-42)$, including $\mathrm{n}$-terminal truncations and modifications. Cortical homogenates were diluted 1:100, and CSF samples were diluted 1:50 in assay buffer and were run according to the manufacturer's protocol.

\section{SDD-AGE}

Semidenaturing detergent agarose gel electrophoresis (SDD-AGE) was performed as previously described. ${ }^{23,24}$ Briefly, $20 \mu \mathrm{g}$ total protein was loaded onto a $1.5 \%$ agarose gel with Laemmli buffer $(20 \mathrm{mmol} / \mathrm{L}$ Tris-base, 200 $\mathrm{mmol} / \mathrm{L}$ glycine, and $0.02 \%$ sodium dodecyl sulfate). The gel was run on ice at $35 \mathrm{~V}$ for 16 hours and then transferred onto polyvinylidene difluoride membrane overnight in TBS using filter paper and capillary action. The membrane was blocked in TBS containing $0.25 \%$ Tween 20 and 5\% nonfat dry milk and incubated overnight with rabbit polyclonal anti-tau (1:4000; AbCam). Horseradish peroxidase-conjugated goat anti-rabbit IgG secondary antibody was applied in blocking solution on day 2 and was detected using chemiluminescent horseradish peroxidase substrate (Thermo Fisher Scientific) and film (GE Healthcare Life Sciences, Pittsburgh, PA).

\section{HEK Cell Seeding Assay}

Stabile CFP/YFP TauRD-expressing HEK293 cells (a gift from Marc Diamond, UT Southwestern Medical Center, Dallas, TX) were grown in polyD lysine-coated 96-well dishes at $3 \times 10^{4}$ cells/well the day before treatment. ${ }^{25}$ Each plate was loaded with samples from a single age cohort (ie, 4 months, 6 months). Numbers were randomly assigned to mice in each cohort, and samples were loaded accordingly to ensure random distribution of genotypes across the plate. Per well, $0.1 \mu \mathrm{g}$ (mouse) or $1 \mu \mathrm{g}$ (human) total protein in $1 \%$ lipofectamine-reduced serum OptiMEM was loaded per well and incubated overnight (12 to 24 hours). For cellular uptake assays, $1 \mu \mathrm{g}$ mouse total protein was loaded without lipofectamine and incubated for 48 hours. Cells were removed from plates with trypsin-EDTA, fixed in $2 \%$ paraformaldehyde for 10 minutes at room temperature, and resuspended in chilled phosphate-buffered saline before being run on a flow cytometer (MACSQuant VYB; Miltenyi Biotec, Cambridge, MA). Cells were first gated on all single cells expressing both CFP and YFP and then on fluorescence resonance energy transfer (FRET). For FRET, cells were illuminated at $405 \mathrm{~nm}$ and CFP-YFP FRET was detected using the 525/50-nm filter. Using the MACSQuantify flow cytometry software version 2.6.1515.13751 (Miltenyi Biotec), the integrated FRET density was measured by multiplying the percentage of FRET-positive population and the median fluorescence intensity of that FRET-positive population. Each sample was run in triplicate. Representative images were taken using $\mathrm{ZOE}$
Fluorescent Cell Imager (Bio-Rad Laboratories, Hercules, CA) using the green fluorescent protein excitation and emission filters.

\section{Statistical Analysis}

All data were analyzed using Statistica version 13 (Dell, Round Rock, TX) or Prism version 6.05 (GraphPad Software, Inc., La Jolla, CA). Except where noted, all data passed Shapiro-Wilk normality tests. No effect of sex on any measurement was observed in APP/PS1-rTg4510 mice. In cases where comparisons were only made between mice carrying $\mathrm{A} \beta$ or tau transgenes, two-tailed $t$-tests for parametric or $U$-tests for nonparametric data sets were performed. In comparisons between all four genotypes, parametric one-way analyses of variance with Sidak or prespecified Bonferroni post hoc comparisons were made where possible. For nonparametric data, Kruskal-Wallis analyses of variance and Dunn multiple comparisons test were used. Human homogenate HEK-seeding assay was analyzed by two-way analysis of variance (plaque status and region) with planned post hoc comparisons between plaques and no plaque cases in each brain region. $P<0.05$ was considered significant. Error bars in all graphs represent \pm SD.

\section{Results}

\section{Accelerated Tau Aggregation in Human Brain}

We hypothesized that tau from human brain with plaques would be more likely to be bioactive (ie, more likely to be in a form that can be taken up and aggregate) than tau extracted from brains in the absence of plaques. ${ }^{26,27}$ To test this hypothesis, we selected tissue from cases that were observed to have tau pathology limited to the entorhinal cortex and hippocampus (Braak stage II) and that either did or did not have amyloid deposits in the cortex (Table 1 and Figure 1). 2,28,29 The former cases are sometimes referred to as primary age-related tauopathy; of note, the tangles in primary age-related tauopathy cases are indistinguishable morphologically or biochemically from those in Alzheimer disease. ${ }^{30}$ Homogenates were prepared from $n=6$ cases without plaques and $n=5$ plaque-containing cases from snap-frozen samples of entorhinal cortex, hippocampus, posterior parahippocampal gyrus, and a control region, the cerebellum (Figure 1, A, B, and E). These homogenates were applied to a well-characterized HEK293 cell-based tau seeding assay. This assay uses a stable cell line expressing the tau (P301S) repeat domain fused to CFP or YFP, which emits a measurable FRET signal when it forms aggregates. ${ }^{25,31}$ We quantified the integrated FRET density (percentage of FRET-positive cells $\times$ median fluorescence intensity) (Figure 1, C and $\mathrm{G}$ ) by flow cytometry. Interestingly, despite comparable amounts of tau, as assessed by ELISA (Figure 1F) (two-way analysis of variance, plaques 
versus no plaques $P=0.790$, brain region $P<0.001$, plaque status $\times$ brain region $P=0.388$ ), hippocampus and parahippocampal gyrus homogenates from cases with plaques resulted in an approximately twofold to threefold enhancement of tau seeding/aggregation compared to those without plaques. This increase was statistically significant in the parahippocampal gyrus (Figure 1, C and G) (two-way analysis of variance, plaques versus no plaques $P=0.0453$; Sidak post hoc multiple comparisons, entorhinal cortex: $P=0.999$, hippocampus: $P=0.573$, parahippocampal gyrus: $P=0.021$ ). We postulate that bioactive tau may be present in synaptic terminals (or neuritic processes derived from projections) of the entorhinal cortex in areas to which it projects strongly (the hippocampus and posterior parahippocampal gyrus). ${ }^{32}$ The cerebellum, a brain region without tangles or plaques, and which does not receive entorhinal projections, did not exhibit tau seeding.

The bioactive tau species capable of seeding aggregate formation has been previously reported to be a highmolecular-weight (HMW) form of phosphorylated tau. ${ }^{26}$ We performed semidenaturing detergent gel electrophoresis (SDD-AGE) to determine whether HMW tau was present in brain samples with plaques versus without plaques (Figure 1D). Both groups had HMW tau present, as observed by SDD-AGE, with regions such as hippocampus and parahippocampal gyrus appearing to have an increase in these species in brains with plaques. Together, this indicates that the presence of plaques enhances tau aggregation in human brain.

\section{Enhanced Tau Pathology in Mice Expressing Both $A \beta$ and Tau}

To further explore this enhancement of tau pathology by $\mathrm{A} \beta$, we produced APP/PS1-rTg4510 mice that express both APP/PS1 and P301L mutant human tau. To characterize this mouse strain, we performed $\mathrm{A} \beta$ and tau histology and assessed gliosis.

Using a pan-A $\beta$ antibody (Supplemental Figure S3, $\mathrm{A}-\mathrm{K})$, plaques were present in both APP/PS1 only (Supplemental Figure S3, A-C) and APP/PS1-rTg4510 crosses (Supplemental Figure S3, E-G). No tau-related difference was observed in the number of plaques at 4 months (Supplemental Figure S3I) $(t$-test, $P=0.220)$ or 6 months (Supplemental Figure S3J) $(P=0.425)$ of age. Fewer plaques were seen in 12-month APP/PS1-rTg4510 mice compared to APP/PS1 alone (Supplemental Figure $\mathrm{S} 3 \mathrm{~K})(P<0.0001)$. At this age, fewer plaques were ThioS $^{+}$(Supplemental Figure S3L) $(P=0.003)$, although the area of each individual plaque was larger (Supplemental Figure S3M) $(P<0.0001)$ in APP/PS1rTg4510 mice. CSF levels of $A \beta 1-42$ were unchanged at 12 months (Supplementary Figure 3N). Homogenates prepared from APP/PS1-rTg4510 mice at 12 months of age also had reduced $A \beta 1-42$ in cortex compared to APP/PS1 only mice, as measured by ELISA (Supplemental Figure S3O) (one-way analysis of variance, $P<0.0001$ ). These results may be confounded by the marked neuronal loss in tau-producing mice compared to APP/PS1 mice by 12 months, reducing the amount of APP and hence A $\beta$ available.

The number of neurons containing phosphorylated tau was quantified at these ages using the AT8 antibody, which recognizes phospho-Ser202/Thr205 (Figure 2, A and B). Compared to rTg4510 mice alone, APP/PS1-rTg4510 mice had more AT8-containing neurons at 4 months ( $t$-test, $P=0.002)$ and 6 months $(P=0.0001)$. At 12 months of age, the difference between genotypes did not reach statistical significance $(P=0.055)$, possibly approaching a ceiling effect. Because changes in phosphorylation at the AT8 epitope precede mature tangle formation, we also specifically examined whether tangle pathology was altered by performing ThioS labeling to detect $\beta$-sheet formation (Figure 2, C and D). Similar to AT8 labeling, there was a marked increase in tangle pathology in the entorhinal cortex of APP/PS1-rTg4510 mice at 4 and 6 months but not at 12 months of age.

We next examined glial cells in these mice to assess a marker of neural system degeneration (Supplemental Figures S4 and S5) and observed increased numbers of glial fibrillary acidic protein-positive astrocytes (Supplemental Figure S4) in cortex of APP/PS1-rTg4510 mice at 6 months (Supplemental Figure S4) (one-way analysis of variance, $P<0.0001)$ and 12 months (Supplemental Figure S4) (Kruskal-Wallis analysis of variance, $P=0.04$ ) of age compared to $\operatorname{rTg} 4510$ alone. Total numbers of microglia (Supplemental Figure S5) were unchanged at any age (one-way analysis of variance, 4 months $P=0.117,6$ months $P=0.6735,12$ months $P=0.099)$, although marked clustering around plaques was observed in APP/PS1 (Supplemental Figure S5) and APP/PS1-rTg4510 (Supplemental Figure S5) mice and is indicative of activation. Thus, the presence of amyloid led to a shift in phenotype with increased phospho-tau aggregation in neurons, tangle formation, and inflammatory markers (astrocytosis) at an earlier age.

\section{Tau Aggregation and Uptake Is Accelerated in Mice with Plaques}

Homogenates prepared from the cortex of mice at each age were next applied to the tau seeding assay to determine whether the presence of plaques altered the seeding bioactivity of tau (Figure 3). As expected, neither wild-type nor APP/PS1 homogenates caused tau seeding at any age (Figure 3A) and were indistinguishable from nontreated HEK cells. By contrast, APP/PS1-rTg4510 mice had greater seeding than $\mathrm{rTg} 4510$ mice at 4 months (Figure 3, A and B) ( $t$-test, $P=0.016)$ and at 6 months $(U$-test, $P=0.015)$ of age. In accord with the results from the histological analysis, there was no difference between these two genotypes ( $t$-test, 
A

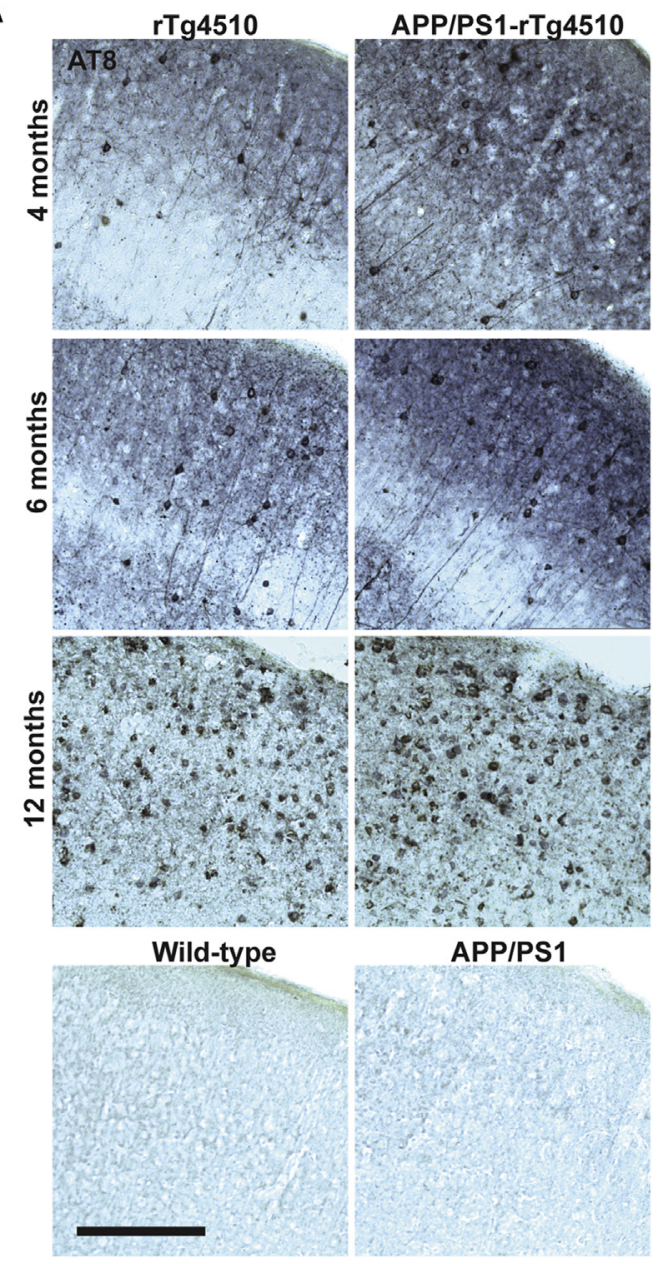

B

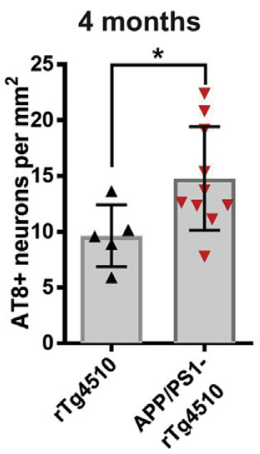

C

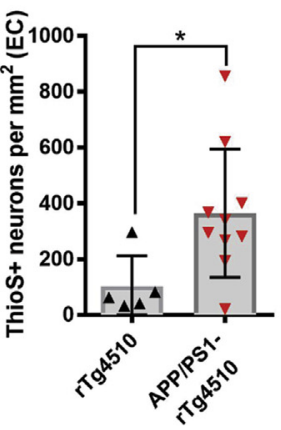

D

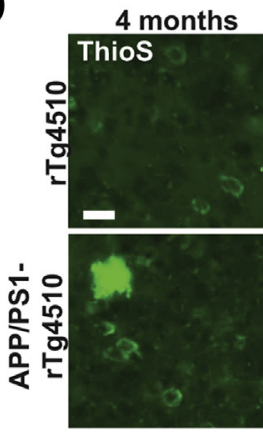

6 months
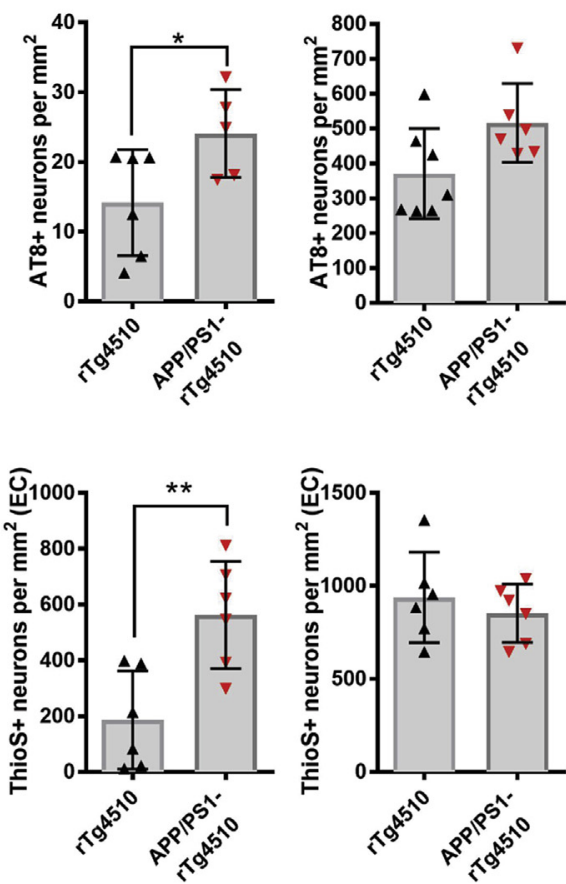

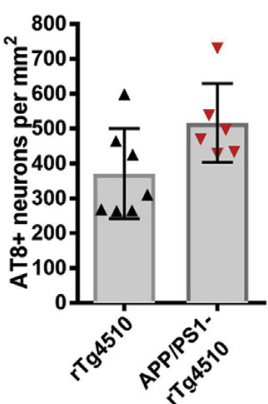

12 months
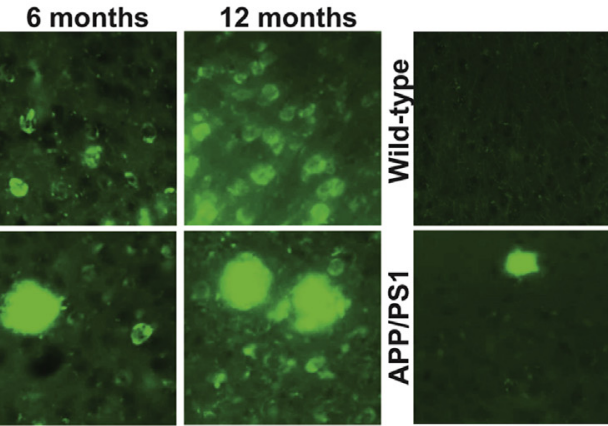

Figure 2 Tau pathology is enhanced in APP/PS1-rTg4510 mice. A: AT8 (pS202/T205 Tau) labeling in somatosensory cortex of rTg4510 and APP/PS1-rTg4510 mice at 4, 6, and 12 months of age. No labeling is observed in wild-type or APP/PS1 mice. B: Quantification of AT8-positive neurons in cortex (t-test). C: Quantification of ThioS tangles in entorhinal cortex of the same mice [U-test (4 months), $t$-test ( 6 and 12 months)]. D: ThioS labeling shows neurofibrillary tangle pathology in rTg4510 and APP/PS1-rTg4510 mice at 4, 6, and 12 months. No ThioS labeling is observed in wild-type mice. Plaques are also apparent in APP/PS1 and APP/PS1-rTg4510 mice. Data are expressed as means \pm SD. ${ }^{*} P<0.05,{ }^{*} P<<0.01$. Scale bars: $200 \mu \mathrm{m}$ (A); $25 \mu \mathrm{m}$ (D). EC, entorhinal cortex.

$P=0.847)$ at 12 months of age, perhaps reflecting a ceiling effect.

We next assessed the ability of tau to be taken up by cells by omitting lipofectamine (the protein carrier used in standard assay conditions) from the seeding assay (Figure 3C). In this configuration, the FRET reporter reflects uptake properties of the tau presented to the cells. Without lipofectamine, tau from 4-month $(U$-test, $P=0.008)$ and 6-month ( $t$-test, $P=0.027)$ APP/PS1-rTg4510 mice induced more aggregates than rTg4510 brain alone. Again, no difference was observed in 12-month mice $(P=0.925)$. We interpret an increase in seeding in the absence of lipofectamine as reflecting an increase in bioactive tau species that allow tau uptake; our earlier studies had suggested that uptake occurs only with the HMW tau species isolated from human brain, and is not observed from the low-molecular-weight species. ${ }^{26}$

\section{No Increase in Extracellular Tau Release or Neuronal Death}

To test the hypothesis that $A \beta$ leads to a change in the level of extracellular tau, which could explain the observed increased formation of aggregates in APP/PS1-rTg4510 mice, we measured CSF levels of total human tau in these mice. CSF tau did not differ between rTg4510 and APP/PS1-rTg4510 mice at any age (Figure 4A) ( $U$-test, 4 months $P=0.412,6$ months $P=0.937 ; t$-test, 12 months $P=0.100)$. Furthermore, CSF tau was highest in mice at 6 months of age (mean, $20.39 \pm 11 \mathrm{ng} / \mathrm{mL}$ in $\mathrm{rTg} 4510$ and $17.49 \pm 8 \mathrm{ng} / \mathrm{mL}$ in APP/ 


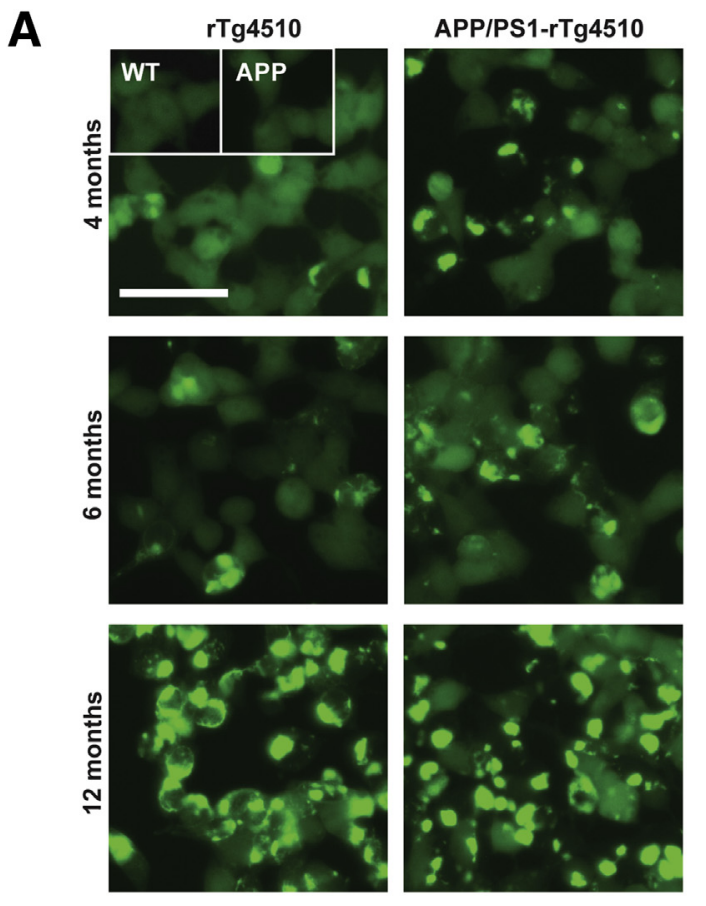

B
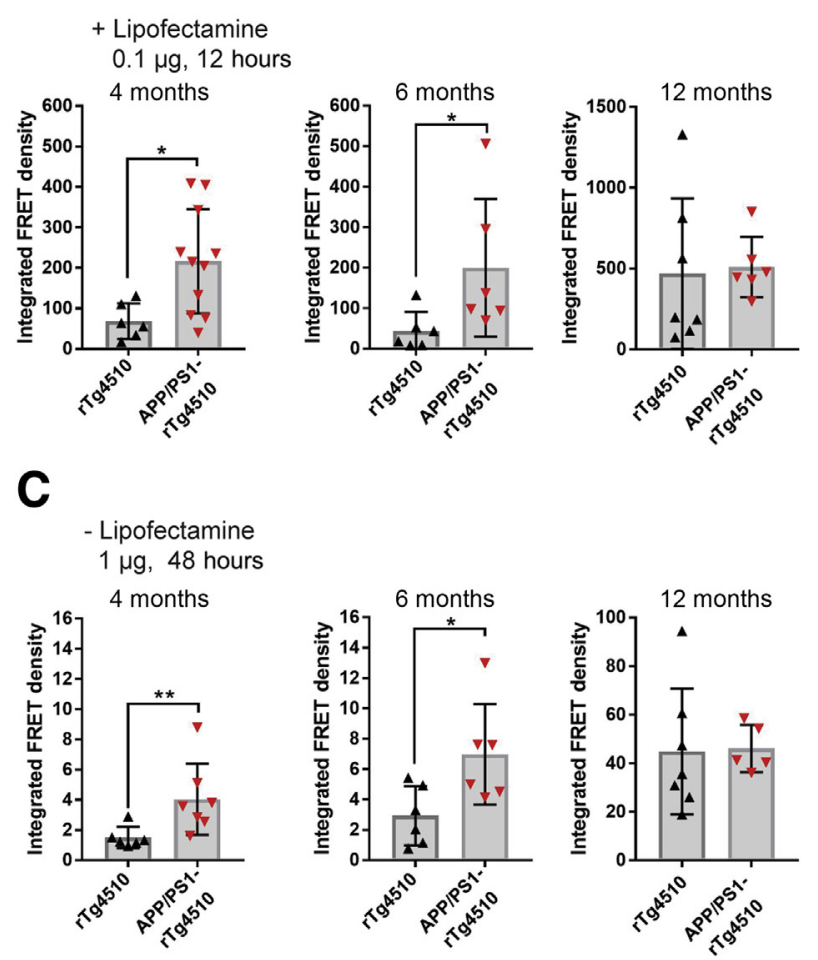

Figure 3 Increased aggregation and uptake of tau in homogenates from APP/PS1-rTg4510 mice. A: Aggregate formation markedly increases in HEK cells in the presence of APP/PS1-rTg4510 homogenates (with lipofectamine, 12 hours after application). No aggregates are seen in cells treated with wildtype (WT) or APP/PS1 homogenates (insets). B: Quantification of aggregate formation in cells treated with $0.1 \mu \mathrm{g}$ protein homogenates in $1 \%$ lipofectamine OPTIMEM [ $t$-test ( 4 and 12 months), $U$-test]. C: Quantification of cell uptake and aggregate formation in cells treated without lipofectamine and 1 $\mu \mathrm{g}$ protein homogenates [ $U$-test (6 months), $t$-test ( 6 and 12 months)]. Data are expressed as means $\pm \mathrm{SD}$. ${ }^{\star} P<0.05,{ }^{*} P P<0.01$. Scale bar $=50 \mu \mathrm{m}(\mathbf{A}$, main images and insets).
PS1-rTg4510) and was reduced at 12 months of age (mean, $6.80 \pm 3.3 \mathrm{ng} / \mathrm{mL}$ in $\mathrm{rTg} 4510$ and $3.85 \pm 1.7 \mathrm{ng} / \mathrm{mL}$ in APP/ PS1-rTg4510), perhaps reflecting the extensive loss of tauproducing neurons by this point in the disease process. No difference between rTg4510 and APP/PS1-rTg4510 mice was observed in the total human-soluble tau content in cortex at any age (Figure 4B) ( $t$-test, 4 months $P=0.109,12$ months $P=0.054$; $U$-test, $P=0.589$ ). Thus, at 4,6 , or 12 months of age, it does not appear that $\mathrm{A} \beta$ alters extracellular steady-state soluble tau levels.

As dying neurons are also a source for extracellular tau release, we also measured cortical volumes from histological sections (Supplemental Figure S6). Tau-overexpressing mice, regardless of the presence of $A \beta$ pathology, showed neuronal loss at advanced age. However, cortical volumes did not differ between rTg4510 only or APP/PS1-rTg4510 mice (Supplemental Figure S6) (Kruskal-Wallis analysis of variance, 4 months $P=0.895$; one-way analysis of variance, 6 months $P=0.348,12$ months $P>0.999$ ) at 4,6 , and 12 months. Cortical volumes were reduced compared to wild-type littermates at 12 months of age (Supplemental Figure S6) (one-way analysis of variance, $P<0.0001$ ), well after the apparent enhancement of tau pathology. Altogether, it does not appear that increased extracellular tau release is responsible for enhanced tau pathology in the presence of $\mathrm{A} \beta$.
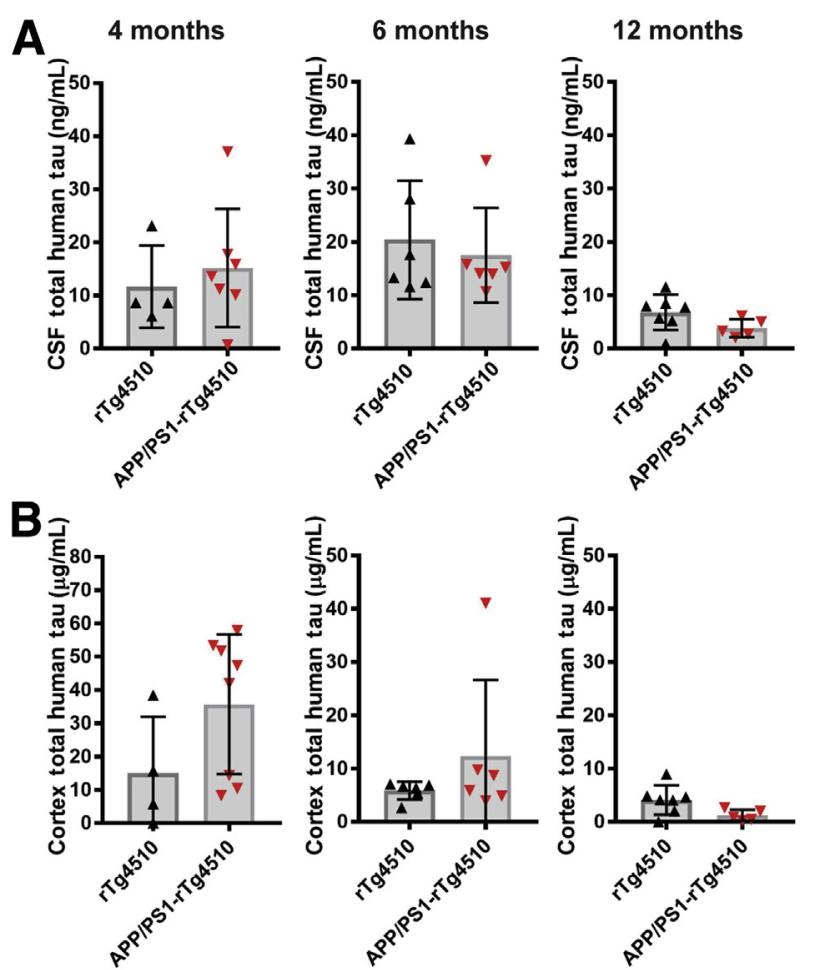

Figure 4 No change in tau release or production in APP/PS1-rTg4510 mice. Cerebrospinal fluid (CSF) levels of extracellular total tau (A) and total tau in cortical homogenates (B) are unchanged between rTg4510 mice and APP/PS1-rTg4510 mice, as measured by ELISA. Data are expressed as means \pm SD. $P=0.054$ (U-test). 
Tau HMW Signature, Solubility, and Phosphorylation in the Presence of $A \beta$

These data suggest that the tau present in APP/PS1-rTg4510 mice is more bioactive than the tau in the $\mathrm{rTg} 4510$ parental strain, particularly in early disease stages. Previous work has indicated that soluble, HMW tau derived from rTg4510 cortex is seed competent and can propagate between neurons, ${ }^{26}$ and data from the early Braak II cases suggest the same. To explore the possibility that tau in APP/PS1rTg4510 mice has similar characteristics by SDD-AGE
(Figure 5, A and B), we examined the extent of soluble tau species in the HMW state. SDD-AGE of cortex homogenates from 4-month-old mice revealed that $\mathrm{rTg} 4510$ mice and APP/PS1-rTg4510 mice appeared to have increased HMW tau at this early age as well.

To further examine changes in tau aggregation, we also performed sarkosyl extraction in 4-month-old mice (Figure 5B). Sarkosyl soluble and insoluble tau was abundant in both rTg4510 and APP/PS1-rTg4510 mice and exhibited similar banding patterns. We also examined nine tau phosphorylation epitopes in rTg4510 and APP/PS1-
A

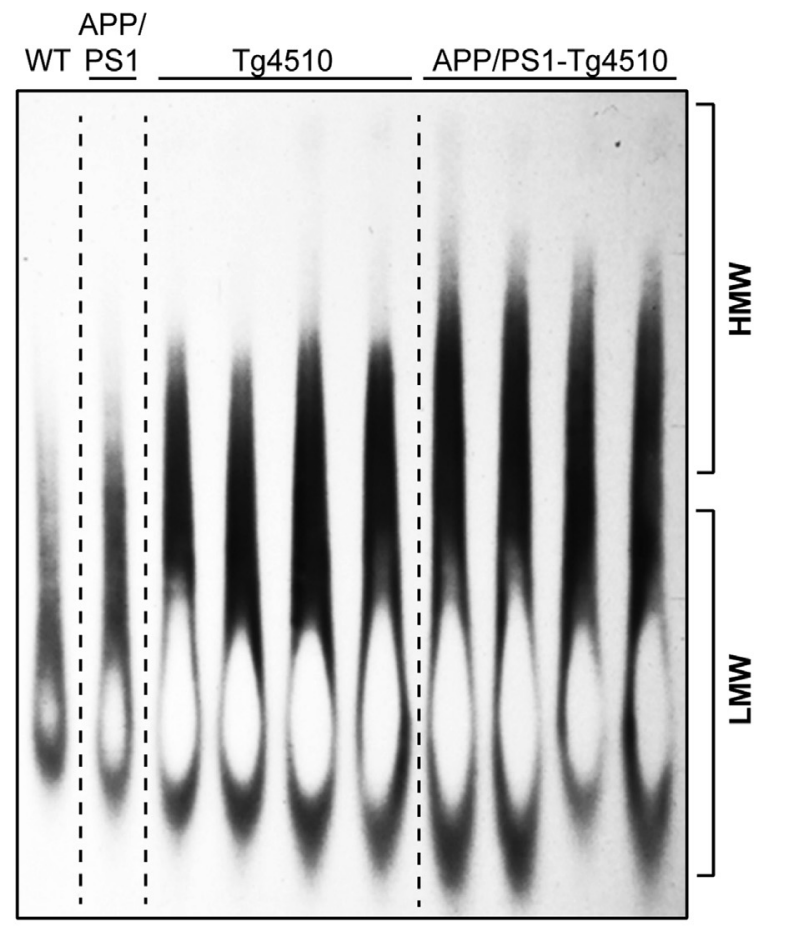

B
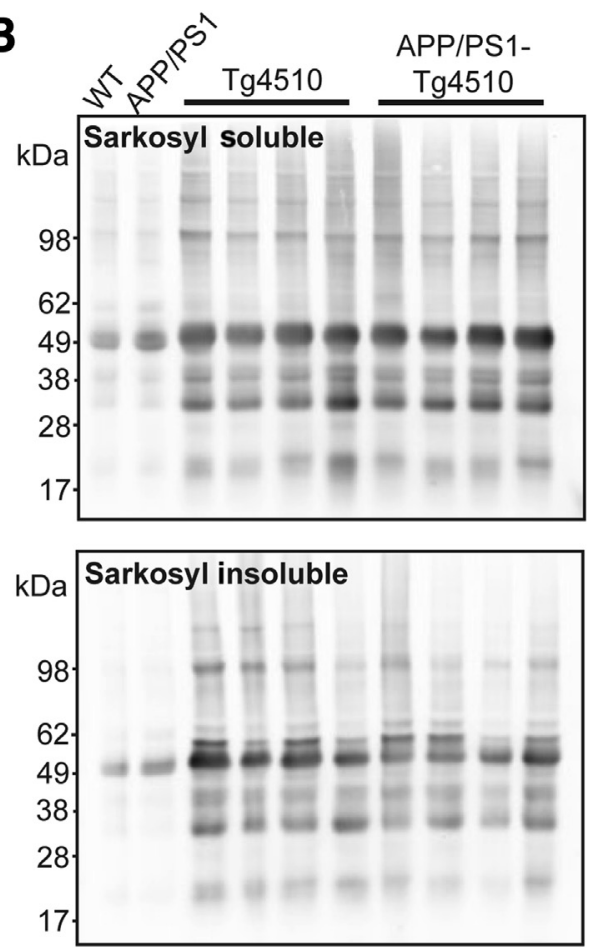
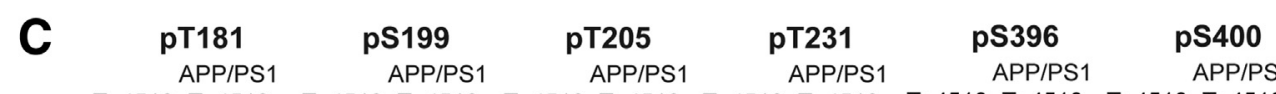

pS422
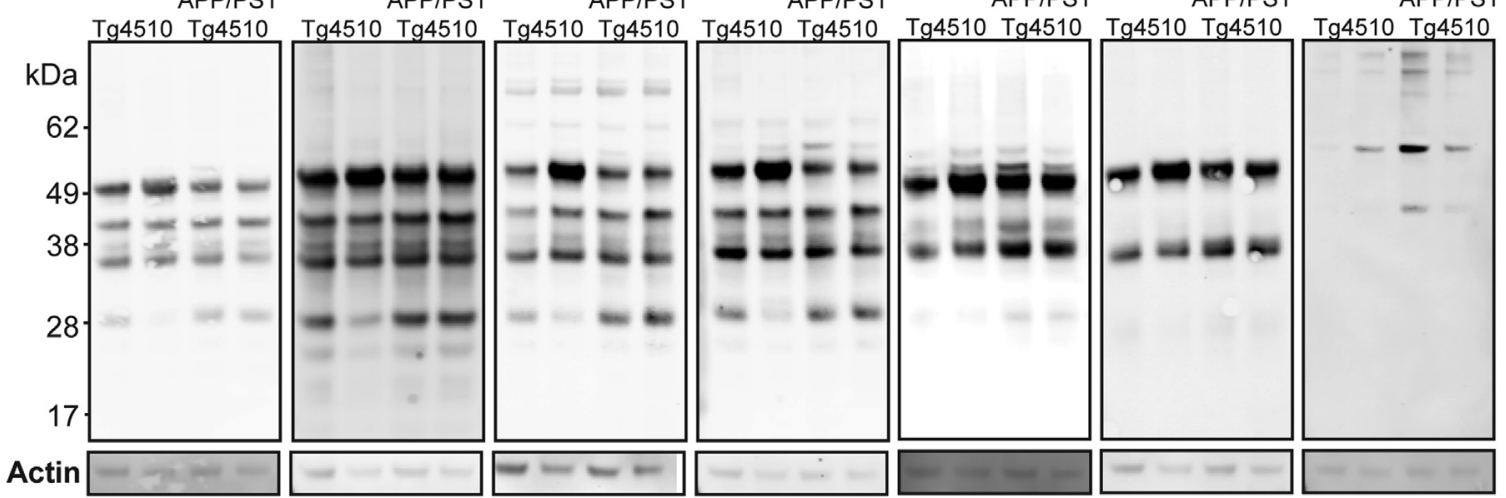

Figure 5 Tau-containing high-molecular-weight (HMW) complexes and phosphorylation at specific epitopes in APP/PS1-rTg4510 mice. A: Cortical homogenates (15 $\mu \mathrm{g}$ total protein) from 4-month-old mice of four different genotypes [wild type (WT)] were loaded on an agarose gel under semidenaturing (SDD-AGE) conditions, and the resulting protein blot was probed with a polyclonal total tau antibody (AbCam). The approximate locations of HMW and lowmolecular-weight (LMW) are noted. Dashed lines indicate divisions between genotypes. B: Western blot of sarkosyl-soluble and sarkosyl-insoluble extracts was also performed and probed using a polyclonal total tau antibody (Dako) in a separate cohort. C: Western blots of seven unique phospho-tau epitopes performed using cortical homogenates from 4-month-old rTg4510 and APP/PS1-rTg4510 mice. Separate blots were used for each phospho-site, with actin shown for loading control. $n=2$ (A and $\mathbf{C})$. 
rTg4510 mice by Western blot (Figure 5C). Phosphorylation was prominent at T181, S199, T205, T231, pS262/ pS356, S396, and S400. Phosphorylation was less apparent at position S422, which appeared to detect mostly HMW SDS-resistant tau and was approximately threefold more abundant in APP/PS1-rTg4510 mice. In all, compared to mice expressing tau only, homogenates from young APP/ PS1-rTg4510 mice had an increase in HMW tau but a similar extent of the sarkosyl insoluble, phosphorylated, and truncated forms.

We assessed these same phospho-epitopes in parahippocampal gyrus homogenates from human cases with and without plaques (Figure 6). We observed few distinctions in banding patterns between cases at these particular sites, although pS199 was reduced in plaque cases (Figure 6) ( $t$-test, $P=0.03$ ). Also, although not statistically significant, pS422 (Figure 6) appeared to detect a slight increase in HMW SDS-resistant tau in samples with plaques, consistent with findings in APP/PS1-rTg4510 mice.

\section{Discussion}

Herein, we explored the possibility that $A \beta$ has a synergistic effect on tau. We observed that tissue from human brains with plaques, compared to tissue that has similar amounts of
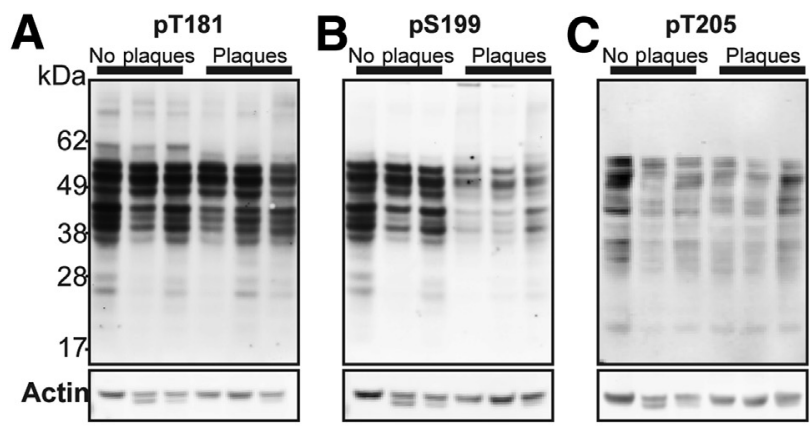

D
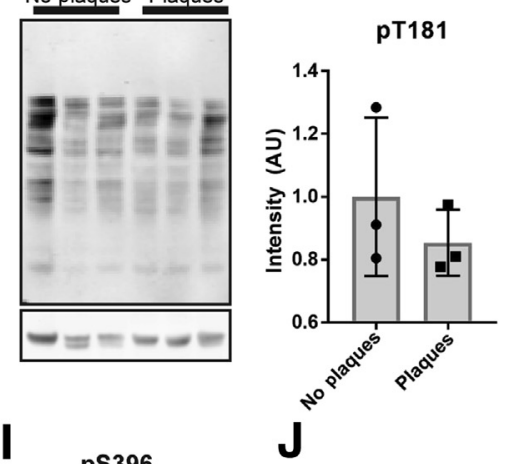

E

$\mathbf{F}$
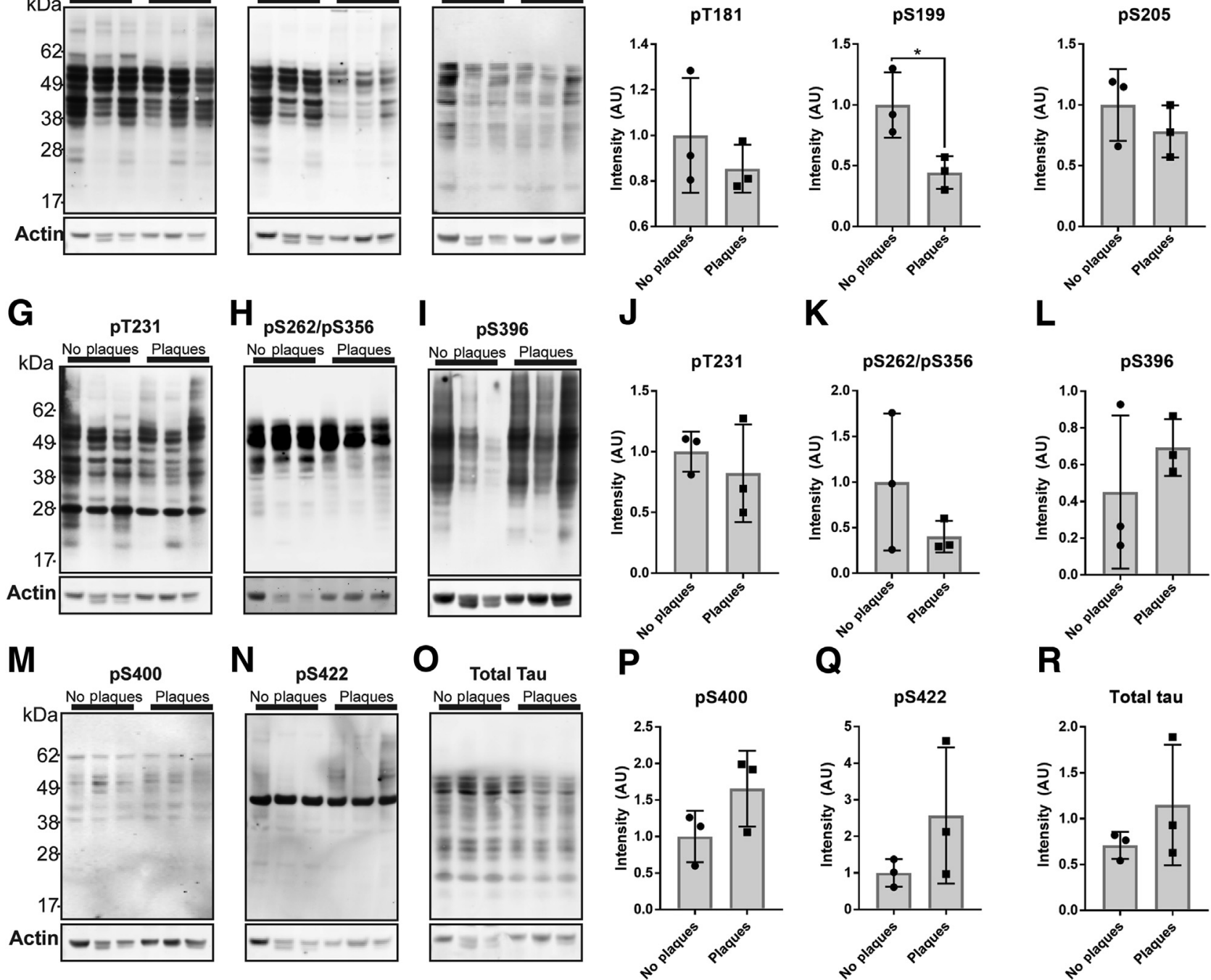

Figure 6 Tau phosphorylation in human Alzheimer disease cases with and without plaques. A-C, G-I, and $\mathbf{M}-\mathbf{0}$ : Western blots of parahippocampal gyrus homogenates from three representative no plaque and three plaque cases were assessed using antibodies to detect phosphorylated tau species. D-F, J-L, and P-R: Bands were quantified by densitometry and normalized to actin loading controls. Phospho-tau species that were assessed include pT181 (A and D), pS199 (B and E), pT205 (C and F), pT231 (G and J), pS262/pS356 (H and K), pS396 ( $\mathbf{I}$ and $\mathbf{~ L ) , ~ p S 4 0 0 ~ ( ~} \mathbf{M}$ and $\mathbf{P})$, and pS422 ( $\mathbf{N}$ and $\mathbf{Q})$. E: Actin shown for the pS396 blot is from a second pS396 blot and is a sample processing control. $\mathbf{0}$ and $\mathbf{R}: \mathbf{A}$ total tau antibody (HT7) that detects the midregion of tau was also used. Separate blots were used for each tau antibody, with actin shown for loading control below. Data are expressed as means \pm SD. ${ }^{\star} P<0.05$ ( $t$-test). $\mathrm{AU}$, arbitrary unit. 
tau but without plaques, results in greater tau seeding activity and an increase in HMW tau species observed by SDD-AGE. These same effects were also observed by crossing the APP/PS1 and $\mathrm{rTg} 4510$ mouse strains. The enhanced ability of tau from APP/PS1-rTg4510 mice at 4 and 6 months of age to seed tau aggregates in an HEK cell bioassay corresponded with increased AT8-positive tau accumulation and ThioS-positive neurofibrillary tangles in mice at these ages. We did not detect a difference in total tau content in cortical homogenates or in CSF tau levels, arguing against the possibility that the increase in the amount of tau pathology was because of a change in tau steady-state levels. In fact, the absolute amount of tau in the CSF decreased substantially as the animals aged, at the same time that there was considerable neuronal death. This inverse relationship suggests that the source of CSF tau is not principally from dying neurons.

Similarly, because previous reports indicate that phosphorylation status of tau is important in uptake and seeding, ${ }^{26}$ we examined the presence of various phosphoepitopes in rTg4510 and APP/PS1-rTg4510 mice and did not detect any large differences. Phospho-epitopes were also similar between human cases with and without plaques, although these assays would not have been sensitive to differences in combinatorial levels of tau phosphorylation. Taken together, these data suggest that $A \beta$ (or a change in the cortex associated with $A \beta$ ) increases the rate of conversion of nonpathological tau to a bioactive form. This increase in bioactive tau, which is both taken up by cells and seeds tau aggregates, is likely responsible for the overall enhancement of tau pathology.

Previously, we tested the hypothesis that the rate at which tau propagates from one region of the brain to another may be one way in which $A \beta$ affects the disease course by examining APP/PS1-TgTauEC mice, which only express tau in the entorhinal cortex. ${ }^{16}$ In those mice, we observed a 20 -fold increase in tau propagation from the entorhinal cortex to the hippocampal dentate gyrus compared to tauonly-expressing mice. ${ }^{16}$ The current data reinforce the idea that $A \beta$ and tau act synergistically to accelerate tau aggregation and deposition.

How $A \beta$ increases tau bioactivity is less clear. One possible mechanism for this effect could be a direct interaction via heterotypic seeding of tau by $A \beta .{ }^{33}$ However, $A \beta$ may also promote aggregate formation through intermediate factors. For example, inflammation is known to enhance tau phosphorylation. ${ }^{34-36}$ Although we did not observe any overt increase in the numbers of microglia present in APP/ PS1-rTg4510 mice versus rTg4510 alone, we saw clustering of microglia near plaques and increased astrocytosis in these mice even at young ages. Thus, inflammatory mediators may be a complementary pathway by which $A \beta$ exerts an effect.

Overall, it would appear that $A \beta$ induces the enhanced formation of bioactive species of tau, which lead to enhanced accumulation in neurons. This acceleration of tau pathology by $A \beta$ is important to our understanding of how Alzheimer disease differs from other tauopathies, and may help explain the observation from clinical studies that tau accumulation in the cortex increases in the presence of detectable amyloid. Moreover, in the animal model, it appears that even soluble $A \beta$ (rather than plaques per se) is sufficient to accelerate tau deposition. Understanding the critical molecular mechanisms that lead to increased high molecular weight, seed competent tau thus may have important therapeutic implications for designing trials testing the idea that reduction of $A \beta$ may affect the rate of accumulation of tau-dependent pathology in Alzheimer disease.

\section{Acknowledgments}

We thank the Neuropathology Core of the Massachusetts Alzheimer's Disease Research Center for tissue samples and assistance with paraffin sections and the patients and families of brain donors; Dr. Marc Diamond for the HEK293 CFP/YFPTauRD cell line; Dr. Susanne Wegmann for her advice in preparation of the manuscript; and Miwei Hu for her assistance with slides.

\section{Supplemental Data}

Supplemental material for this article can be found at http://dx.doi.org/10.1016/j.ajpath.2017.03.011.

\section{References}

1. Braak H, Braak E: Neuropathological stageing of Alzheimer-related changes. Acta Neuropathol 1991, 82:239-259

2. Thal DR, Rüb U, Orantes M, Braak H: Phases of A beta-deposition in the human brain and its relevance for the development of AD. Neurology 2002, 58:1791-1800

3. Arriagada PV, Growdon JH, Hedley-Whyte ET, Hyman BT: Neurofibrillary tangles but not senile plaques parallel duration and severity of Alzheimer's disease. Neurology 1992, 42:631-639

4. Bierer LM, Hof PR, Purohit DP, Carlin L, Schmeidler J, Davis KL, Perl DP: Neocortical neurofibrillary tangles correlate with dementia severity in Alzheimer's disease. Arch Neurol 1995, 52:81-88

5. Bolmont T, Clavaguera F, Meyer-Luehmann M, Herzig MC, Radde R, Staufenbiel M, Lewis J, Hutton M, Tolnay M, Jucker M: Induction of tau pathology by intracerebral infusion of amyloid- $\beta$-containing brain extract and by amyloid- $\beta$ deposition in APP $\times$ Tau transgenic mice. Am J Pathol 2007, 171:2012-2020

6. Héraud C, Goufak D, Ando K, Leroy K, Suain V, Yilmaz Z, De Decker R, Authelet M, Laporte V, Octave JN, Brion JP: Increased misfolding and truncation of tau in APP/PS1/tau transgenic mice compared to mutant tau mice. Neurobiol Dis 2014, 62:100-112

7. Hurtado DE, Molina-Porcel L, Iba M, Aboagye AK, Paul SM, Trojanowski JQ, Lee VM: A $\beta$ accelerates the spatiotemporal progression of tau pathology and augments tau amyloidosis in an Alzheimer mouse model. Am J Pathol 2010, 177:1977-1988

8. Pérez M, Ribe E, Rubio A, Lim F, Morán MA, Ramos PG, Ferrer I, Isla MTG, Avila J: Characterization of a double (amyloid precursor protein-tau) transgenic: tau phosphorylation and aggregation. Neuroscience 2005, 130:339-347 
9. Ribé EM, Pérez M, Puig B, Gich I, Lim F, Cuadrado M, Sesma T, Catena S, Sánchez B, Nieto M, Gómez-Ramos P, Morán MA, Cabodevilla F, Samaranch L, Ortiz L, Pérez A, Ferrer I, Avila J, Gómez-Isla T: Accelerated amyloid deposition, neurofibrillary degeneration and neuronal loss in double mutant APP/tau transgenic mice. Neurobiol Dis 2005, 20:814-822

10. Saul A, Sprenger F, Bayer TA, Wirths O: Accelerated tau pathology with synaptic and neuronal loss in a novel triple transgenic mouse model of Alzheimer's disease. Neurobiol Aging 2013, 34:2564-2573

11. Seino Y, Kawarabayashi T, Wakasaya Y, Watanabe M, Takamura A, Yamamoto-Watanabe Y, Kurata T, Abe K, Ikeda M, Westaway D, Murakami T, Hyslop PSG, Matsubara E, Shoji M: Amyloid $\beta$ accelerates phosphorylation of tau and neurofibrillary tangle formation in an amyloid precursor protein and tau double-transgenic mouse model. J Neurosci Res 2010, 88:3547-3554

12. Forny-Germano L, Lyra e Silva NM, Batista AF, Brito-Moreira J, Gralle M, Boehnke SE, Coe BC, Lablans A, Marques SA, Martinez AMB, Klein WL, Houzel JC, Ferreira ST, Munoz DP, De Felice FG: Alzheimer's disease-like pathology induced by amyloid$\beta$ oligomers in nonhuman primates. $J$ Neurosci 2014, 34: 13629-13643

13. Oddo S, Caccamo A, Shepherd JD, Murphy MP, Golde TE, Kayed R, Metherate R, Mattson MP, Akbari Y, LaFerla FM: Triple-transgenic model of Alzheimer's disease with plaques and tangles: intracellular Abeta and synaptic dysfunction. Neuron 2003, 39:409-421

14. Götz J, Chen F, van Dorpe J, Nitsch RM, Lewis J: Formation of neurofibrillary tangles in P3011 tau transgenic mice induced by Abeta 42 fibrils. Science 2001, 293:1491-1495

15. Lewis J, Dickson DW, Lin WL, Chisholm L, Corral A, Jones G, Yen SH, Sahara N, Skipper L, Yager D, Eckman C, Hardy J, Hutton M, McGowan E: Enhanced neurofibrillary degeneration in transgenic mice expressing mutant tau and APP. Science 2001, 293: $1487-1491$

16. Pooler AM, Polydoro M, Maury EA, Nicholls SB, Reddy SM, Wegmann S, William C, Saqran L, Cagsal-Getkin O, Pitstick R, Beier DR, Carlson GA, Spires-Jones TL, Hyman BT: Amyloid accelerates tau propagation and toxicity in a model of early Alzheimer's disease. Acta Neuropathol Commun 2015, 3:14

17. Hyman BT, Phelps CH, Beach TG, Bigio EH, Cairns NJ, Carrillo MC, Dickson DW, Duyckaerts C, Frosch MP, Masliah E, Mirra SS, Nelson PT, Schneider JA, Thal DR, Thies B, Trojanowski JQ, Vinters HV, Montine TJ: National Institute on Aging-Alzheimer's Association guidelines for the neuropathologic assessment of Alzheimer's disease. Alzheimers Dement 2012, 8:1-13

18. Mayford M, Bach ME, Huang YY, Wang L, Hawkins RD, Kandel ER: Control of memory formation through regulated expression of a CaMKII transgene. Science 1996, 274:1678-1683

19. Jankowsky JL, Fadale DJ, Anderson J, Xu GM, Gonzales V, Jenkins NA, Copeland NG, Lee MK, Younkin LH, Wagner SL, Younkin SG, Borchelt DR: Mutant presenilins specifically elevate the levels of the 42 residue beta-amyloid peptide in vivo: evidence for augmentation of a 42-specific gamma secretase. Hum Mol Genet 2004, $13: 159-170$

20. Jankowsky JL, Slunt HH, Ratovitski T, Jenkins NA, Copeland NG, Borchelt DR: Co-expression of multiple transgenes in mouse CNS: a comparison of strategies. Biomol Eng 2001, 17:157-165

21. Santacruz K, Lewis J, Spires T, Paulson J, Kotilinek L, Ingelsson M, Guimaraes A, DeTure M, Ramsden M, McGowan E, Forster C, Yue M, Orne J, Janus C, Mariash A, Kuskowski M, Hyman B, Hutton M, Ashe KH: Tau suppression in a neurodegenerative mouse model improves memory function. Science 2005, 309:476-481

22. Carlson GA, Borchelt DR, Dake A, Turner S, Danielson V, Coffin JD, Eckman C, Meiners J, Nilsen SP, Younkin SG, Hsiao KK: Genetic modification of the phenotypes produced by amyloid precursor protein overexpression in transgenic mice. Hum Mol Genet 1997, 6: 1951-1959

23. Sanders DW, Kaufman SK, DeVos SL, Sharma AM, Mirbaha H, Li A, Barker SJ, Foley AC, Thorpe JR, Serpell LC, Miller TM, Grinberg LT, Seeley WW, Diamond MI: Distinct Tau prion strains propagate in cells and mice and define different tauopathies. Neuron 2014, 82: $1271-1288$

24. Halfmann R, Lindquist S: Screening for amyloid aggregation by semidenaturing detergent-agarose gel electrophoresis. J Vis Exp 2008, 17 : 838

25. Holmes BB, Furman JL, Mahan TE, Yamasaki TR, Mirbaha H, Eades WC, Belaygorod L, Cairns NJ, Holtzman DM, Diamond MI: Proteopathic tau seeding predicts tauopathy in vivo. Proc Natl Acad Sci U S A 2014, 111:E4376-E4385

26. Takeda S, Wegmann S, Cho H, DeVos SL, Commins C, Roe AD, Nicholls SB, Carlson GA, Pitstick R, Nobuhara CK, Costantino I, Frosch MP, Müller DJ, Irimia D, Hyman BT: Neuronal uptake and propagation of a rare phosphorylated high-molecular-weight tau derived from Alzheimer's disease brain. Nat Commun 2015, 6:8490

27. Usenovic M, Niroomand S, Drolet RE, Yao L, Gaspar RC, Hatcher NG, Schachter J, Renger JJ, Parmentier-Batteur S: Internalized tau oligomers cause neurodegeneration by inducing accumulation of pathogenic tau in human neurons derived from induced pluripotent stem cells. J Neurosci 2015, 35:14234-14250

28. Braak H, Alafuzoff I, Arzberger T, Kretzschmar H, Del Tredici K: Staging of Alzheimer disease-associated neurofibrillary pathology using paraffin sections and immunocytochemistry. Acta Neuropathol 2006, 112:389-404

29. Mirra SS, Heyman A, McKeel D, Sumi SM, Crain BJ, Brownlee LM, Vogel FS, Hughes JP, van Belle G, Berg L: The Consortium to Establish a Registry for Alzheimer's Disease (CERAD), part II: standardization of the neuropathologic assessment of Alzheimer's disease. Neurology 1991, 41:479-486

30. Crary JF, Trojanowski JQ, Schneider JA, Abisambra JF, Abner EL, Alafuzoff I, et al: Primary age-related tauopathy (PART): a common pathology associated with human aging. Acta Neuropathol 2014, 128: 755-766

31. Kfoury N, Holmes BB, Jiang H, Holtzman DM, Diamond MI: Transcellular propagation of tau aggregation by fibrillar species. J Biol Chem 2012, 287:19440-19451

32. Tai HC, Serrano-Pozo A, Hashimoto T, Frosch MP, Spires-Jones TL, Hyman BT: The synaptic accumulation of hyperphosphorylated tau oligomers in Alzheimer disease is associated with dysfunction of the ubiquitin-proteasome system. Am J Pathol 2012, 181:1426-1435

33. Vasconcelos B, Stancu IC, Buist A, Bird M, Wang P, Vanoosthuyse A, Van Kolen K, Verheyen A, Kienlen-Campard P, Octave JN, Baatsen P, Moechars D, Dewachter I: Heterotypic seeding of Tau fibrillization by pre-aggregated Abeta provides potent seeds for prion-like seeding and propagation of Tau-pathology in vivo. Acta Neuropathol 2016, 131: $549-569$

34. Bhaskar K, Konerth M, Kokiko-Cochran ON, Cardona A, Ransohoff RM, Lamb BT: Regulation of tau pathology by the microglial fractalkine receptor. Neuron 2010, 68:19-31

35. Kitazawa M, Oddo S, Yamasaki TR, Green KN, LaFerla FM: Lipopolysaccharide-induced inflammation exacerbates Tau pathology by a cyclin-dependent kinase 5-mediated pathway in a transgenic model of Alzheimer's disease. J Neurosci 2005, 25:8843-8853

36. Gorlovoy P, Larionov S, Pham TTH, Neumann H: Accumulation of tau induced in neurites by microglial proinflammatory mediators. FASEB J 2009, 23:2502-2513 